\title{
Silindirik beton numunelerde boy/çap oranı değişiminin basınç dayanımına etkisi
}

\section{The effect of length/diameter ratio change of cylinder concrete specimens on compressive strength}

\author{
Uğur Durak ${ }^{1, *}$ (iD \\ ${ }^{1}$ Erciyes Üniversitesi, Mühendislik Fakültesi, İnşaat Mühendisliği Bölümü, 38039, Kayseri, Türkiye
}

\begin{abstract}
Özet
$\mathrm{Bu}$ çalışmada silindirik numunelerde boy/çap oranı değişiminin basınç dayanım üzerindeki etkisi araştırılmıştır. Bu amaçla CEM I 42.5 R çimento kullanılarak su/bağlayıcı oranı 0.62 olan beton elemanlar üretilmiştir. Üretilen betonlardan karot makinası kullanılarak 50, 75, 100, 125 ve $150 \mathrm{~mm}$ çaplarında karot numuneleri alınmıştır. Alınan karot numuneleri laboratuvar ortamında taş kesme makinası ile kesilerek her bir çap için boy/çap oranı $0.5,1.0,1.5$ ve 2.0 olan numuneler elde edilmiştir. Elde edilen numuneler üzerinde basınç dayanımı deneyi gerçekleştirilmiştir. Elde edilen sonuçlara göre boy/çap oranını artışı ile genel olarak numunelerin basınç dayanımlarında azalmalar görülmüştür. Ayrıca boy/çap oranı ve basınç dayanımı arasında $\mathrm{R}^{2}=0.88$ 'e varan oranlarda doğrusal bir ilişki olduğu belirlenmiştir.
\end{abstract}

Anahtar kelimeler: Beton, Basınç dayanımı, Boy/Çap oran1.

\section{Giriş}

Beton elemanlarda su/çimento oranı, karma suyu, çimento özellikleri, agrega özellikleri, betona uygulanan karılma, taşıma, yerleştirme ve sıkıştırma işlemleri, kür koşulları, betonun yaşı ve deneyde kullanılan numunelerin şekil ve boyutları gibi birçok parametre, betonun basınç dayanımını etkilemektedir [1-3].

Genel olarak beton numunelerde kirılma durumu incelendiğinde kırılmanın kuvvet yönünde gelişen düşey çatlakların açılması sonucunda meydana geldiği görülmektedir. Deney cihazı tablası ile beton numunesi arasındaki sürtünme kuvveti ise bu çatlakların açılmasını engellemektedir. Boy/çap oranı düşük olan (basık) elemanlarda bu sürtünme etkisi daha yüksek olmakta ve bu nedenle çatlakların açılması zorlanmaktadır. Bu durum doğal olarak basınç dayanımının daha yüksek olmasını sağlamaktadır. Ayrıca beton elemanlarda kesit alanı büyüdükçe beton bünyesinde kusurlu bölge (çatlak, boşluk v.b.) bulunma ihtimali de artmaktadir. Bu durum da beton numunelerin basınç dayanımında azalmalara neden olabilmektedir [1].

Beton elemanların şekil ve boyutlarına bağlı olarak ortaya çıkan bu durum nedeniyle günümüz

\section{Abstract}

In this study, the effect of the change in length/diameter ratio on the compressive strength in cylindrical specimens was investigated. For this purpose, specimens with a water / binder ratio of 0.62 were produced using CEM I $42.5 \mathrm{R}$ cement. Core samples of 50, 75, 100, 125 and $150 \mathrm{~mm}$ diameters were taken from the produced concretes by using the core drilling machine. The core samples taken were cut with a stone cutting machine in the laboratory environment and samples with the length / diameter ratio of $0.5,1.0,1.5$ and 2.0 were obtained for each diameter. Compressive strength test was carried out on the samples obtained. According to the results, with the increase in the length / diameter ratio, generally the compressive strength of the samples decreased. In addition, it has been determined that there is a linear relationship of up to $\mathrm{R}^{2}=0.88$ between length / diameter ratio and compressive strength.

Keywords: Concrete, Compressive strength, Length/diameter ratio.

yönetmeliklerinde, beton basınç dayanımı yapılacak numuneler şekil ve boyut açısında standartlaştırılmıştır. Ülkemizde yürürlükte olan TS 13515 [4] standardına göre beton basınç dayanımının tespit edilebilmesi için silindirik numuneler için boy/çap oranı 2 olan $100 \times 200 \mathrm{~mm}$ veya $150 \times 300 \mathrm{~mm}($ çap $\times$ boy) boyutlarındaki numuneler $[5,6]$, küp numuneler için ise $100 \times 100 \times 100 \mathrm{~mm}$ veya $150 \times 150 \times 150 \mathrm{~mm}$ boyutlarındaki numuneler [7-9] kullanılmaktadır.

Diğer taraftan beton numunelerde şekil, boyut ve beton yerleştirme yönüne bağlı olarak ortaya çıkan dayanım farklılıkları birçok araştırmacı tarafından araştırılmıştır. [1017]. Bu araştırmalardan bazıları özet olarak sunulmuştur

Yi ve arkadaşları [18], yapmış oldukları çalışmada beton numunelerin şekil, boyut ve beton yerleştirme yönüne göre basınç dayanımı değişimlerini incelemişlerdir. Çalışma kapsamında farklı boyutlarda silindirik, kübik ve prizmatik numuneler kullanmışlardır. Elde ettikleri sonuçlara göre numune boyutları arttıkça basınç dayanımlarının azaldığını tespit etmişlerdir.

Sert [19], yapmış olduğu laboratuvar çalışmasında beton karot dayanımları ile standart beton basınç dayanımı arasındaki ilişkiyi karot çapına bağlı olarak araştırmıştır.

\footnotetext{
* Sorumlu yazar / Corresponding author, e-posta / e-mail: ugurdurak@erciyes.edu.tr (U. Durak)

Geliș / Recieved: 06.02.2021 Kabul / Accepted: 15.03.2021 Yayımlanma / Published: 27.07.2021

doi: $10.28948 /$ ngmuh. 875574
} 
Çalışmasında 50, 100 ve $150 \mathrm{~mm}$ boyutlarında farklı boy/çap oranlarında karot numuneleri kullanmıștır. Elde ettiği sonuçlara göre 50,100 ve $150 \mathrm{~mm}$ çaplı karot numunelerinde boy/çap oranı arttıkça basınç dayanımlarının düştüğünü gözlemlemiştir. Ayrıca beton yerleştirme yönünün basınç dayanımı etkilediğini ve yerleştirme yönünde alınan karot numunelerinin daha yüksek basınç dayanımı verdiğini tespit etmiştir.

Tokyay ve Özdemir [20] yapmış oldukları yüksek dayanımlı betonlarda numune boyut ve şekillerinin beton dayanımına etkisini araştırmışlardır. $\mathrm{Bu}$ amaçla farklı boy/çap oranlarında silindirik ve farklı boyutlarda kübik numuneler üretmişlerdir. Elde ettikleri sonuçlara yüksek dayanımlı betonlarda, küçük boyutlu numunelerin standart numuneler gibi yüksek dayanımlar sağlayamadığını gözlemlemişlerdir. Bu durumu küçük boyutlu numunelerde yanal yüzey alanı/hacim oranının yüksek olması sebebiyle ortaya çıkan duvar etkisine bağlamışlardır. Ayrıca silindir numunelerde boy/çap oranı değişiminin yüksek dayanımlı betonlar için önemsiz olduğunu vurgulamışlardır.

Literatürde yer alan çalışmalarda beton elemanlarda silindirik numunelerde boy/çap oranı değişiminin basınç dayanımına etkisi üzerinde farklı görüşler ileri sürülmüştür. Bu nedenle bu çalışmada boy/çap oranı $0.5,1.0,1.5$ ve 2.0 olan $50,75,100,125$ ve $150 \mathrm{~mm}$ çapındaki beton numunelere basınç dayanımı deneyi yapılarak, silindirik beton numunelerde boy/çap oranı değişiminin basınç dayanımı üzerindeki etkisi deneysel olarak incelenmiştir.

\section{Materyal ve metot}

Çalışmada kullanılan numuneler CEM I 42,5 R normal Portland çimentosu kullanılarak imal edilmiştir. Kullanılan çimentonun özgül ağırlığı 3.16, priz başlangıç süresi $134 \mathrm{dk}$, priz bitiş süresi $228 \mathrm{dk}$ ve özgül yüzeyi $3220 \mathrm{~cm}^{2} / \mathrm{g}$ olarak belirlenmiştir. Çimentonun kimyasal kompozisyonu Tablo 1'de sunulmuştur. Çalışmada agrega olarak 0-4 mm tane büyüklüğünde ince agrega ve 4-16 mm tane büyüklüğünde iri agrega kullanılmıştır. Agrega tane büyüklüğü dağılımları TS EN 933-1 [21] standardına uygun olarak elek analizi yapılarak belirlenmiştir. İnce ve iri agreganın kuru yüzey doygun özgül ağırlıkları sırasıyla 2.64 ve $2.60 \mathrm{~g} / \mathrm{cm}^{3}$ 'tür. Su emme kapasiteleri ise sırasıyla $\% 1.30$ ve $\% 1.17$ olarak ölçülmüştür. Çalışmada akışkanlaştırıcı olarak \%1.5 oranında Glenium 51 hiper akışkanlaştırıcı kullanılmıştır. Numuneler şebeke suyu kullanılarak üretilmiştir.

Beton üretimini gerçekleştirmek için TS-802 [22] standardına uygun olarak beton karışım hesabı yapılmıştır. Beton karışım hesabına göre $1 \mathrm{~m}^{3}$ beton üretimi için kullanılacak malzeme miktarları belirlenmiş ve Tablo 2'de sunulmuştur.

Tablo 2'de verilen malzeme oranları kullanılarak beton üretimi gerçekleştirilmiş ve hazırlanan kalıplara beton vibratör kullanılarak yerleştirilmiştir. Beton döküm ve bakım işlemleri TS 1247 [23] standardına uygun olarak gerçekleştirilmiştir. 28 gün boyunca kür edilen beton elemanlardan TS EN 12504-1 [24] standardına uygun olarak karot makinası kullanılarak 50, 75, 100, 125 ve $150 \mathrm{~mm}$ çaplarında silindirik karot numuneleri alınmıştır.
Tablo 1. Çimentonun kimyasal kompozisyonu

\begin{tabular}{cccc}
\hline Oksit & $\%$ & Oksit & $\%$ \\
\hline $\mathrm{CaO}$ & 61.77 & Serbest $\mathrm{CaO}$ & 0.93 \\
$\mathrm{SiO}_{2}$ & 19.82 & $\mathrm{~K}_{2} \mathrm{O}$ & 0.83 \\
$\mathrm{Al}_{2} \mathrm{O}_{3}$ & 5.46 & $\mathrm{Na}_{2} \mathrm{O}$ & 0.31 \\
$\mathrm{Fe}_{2} \mathrm{O}_{3}$ & 3.74 & $\mathrm{Mn}_{2} \mathrm{O}_{3}$ & 0.17 \\
$\mathrm{SO}_{3}$ & 2.78 & $\mathrm{KK}$ & 0.98 \\
$\mathrm{MgO}$ & 2.59 & Diğer & 0.62 \\
\hline
\end{tabular}

Tablo $2.1 \mathrm{~m}^{3}$ beton üretimi için malzeme miktarları

\begin{tabular}{lc}
\hline Malzeme & Miktar $(\mathrm{kg})$ \\
\hline Çimento & 300 \\
$0-4 \mathrm{~mm}$ agrega & 1035 \\
$4-16 \mathrm{~mm}$ agrega & 847 \\
Su & 185 \\
Kimyasal Katk1 & 4.5 \\
\hline
\end{tabular}

Alınan karot numuneleri laboratuvarda taş kesme makinasında her iki yüzeyi de düzgün olacak şekilde kesilerek her bir çap için boy/çap oranı $0.50,1.0,1.5$ ve 2.0 olan ikişer adet numune elde edilmiştir. Elde edilen silindirik numunelerin alt ve üst kısımlarına, pürüzsüz bir yüzey elde etmek için kükürt-grafit tozu eriyiği ile başlık yapılmıştır. Deneye hazır hale gelen numuneler üzerinde TS EN 123903 [25] standardına uygun olarak basınç dayanımı deneyi gerçekleştirilmiştir. Karot numunelerin alınması ve deneye hazırlık aşamaları Şekil 1'de, elde edilen numuneler ve deney cihazı Şekil 2'de sunulmuştur.

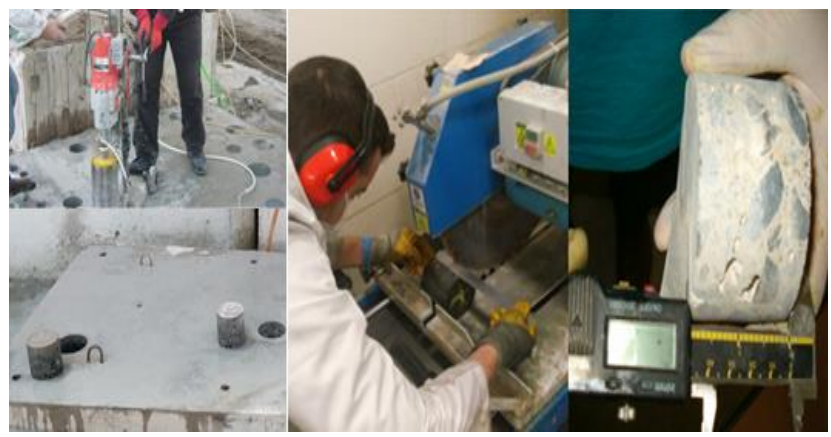

Şekil 1. Deney numunelerinin hazırlanması

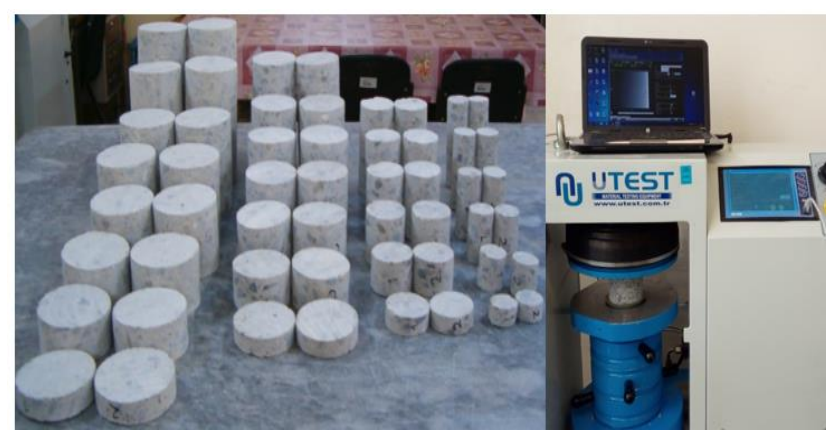

Şekil 2. Hazırlanan numuneler ve deney cihazı 


\section{Bulgular ve tartışma}

Her bir çap ve boy/çap oranı için gerçekleştirilen basınç dayanımı deney sonuçları Tablo 3'de sunulmuştur. Elde edilen basınç dayanımı deney sonuçlarına göre $50 \mathrm{~mm}$ çaplı numunelerde basınç dayanımları $0.5,1.0,1.5$ ve 2.0 boy/çap oranları için sırasıyla $36.8,29.8,28.7$ ve $28.2 \mathrm{MPa}$ olarak belirlenmiştir. $50 \mathrm{~mm}$ çaplı numunelerde boy/çap oranının artması ile basınç dayanımlarında azalmalar gözlenmiştir. Boy/çap oranı $0.5,1.0$ ve 1.5 olan numunelerin basınç dayanımları, boy/çap oranı 2.0 olması durumunda sırasıyla $\% 23.3, \% 5.4$ ve \%1.7'ye varan oranlarda azalmıştır. $50 \mathrm{~mm}$ çaplı numuneler için boy/çap oranı ve basınç dayanımları arasındaki ilişki incelendiğinde $\mathrm{R}^{2}=0.7515$ olacak şekilde doğrusal bir ilişki olduğu belirlenmiştir (Şekil 3).

Tablo 3. Basınç dayanımı deney sonuçları

\begin{tabular}{|c|c|c|}
\hline $\begin{array}{l}\text { Numune Çap } 1 \\
(\mathrm{~mm})\end{array}$ & $\begin{array}{c}\text { Boy/Çap } \\
\text { Oranı }\end{array}$ & $\begin{array}{c}\text { Basınç Dayanımı } \\
(\mathrm{MPa})\end{array}$ \\
\hline 50 & 0.50 & 36.8 \\
\hline 50 & 1.00 & 29.8 \\
\hline 50 & 1.50 & 28.7 \\
\hline 50 & 2.00 & 28.2 \\
\hline 75 & 0.50 & 35.3 \\
\hline 75 & 1.00 & 29.2 \\
\hline 75 & 1.50 & 27.5 \\
\hline 75 & 2.00 & 26.5 \\
\hline 100 & 0.50 & 34.5 \\
\hline 100 & 1.00 & 29.0 \\
\hline 100 & 1.50 & 26.9 \\
\hline 100 & 2.00 & 25.9 \\
\hline 125 & 0.50 & 34.2 \\
\hline 125 & 1.00 & 27.7 \\
\hline 125 & 1.50 & 26.2 \\
\hline 125 & 2.00 & 25.7 \\
\hline 150 & 0.50 & 33.7 \\
\hline 150 & 1.00 & 26.9 \\
\hline 150 & 1.50 & 25.1 \\
\hline 150 & 2.00 & 24.5 \\
\hline
\end{tabular}

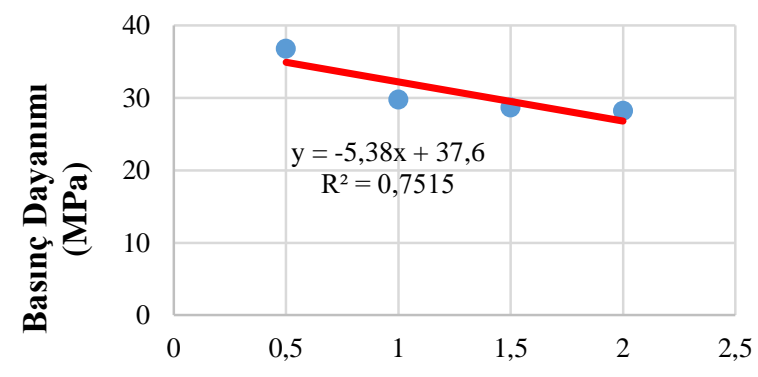

Boy/Çap Oranı

Şekil 3. $50 \mathrm{~mm}$ çaplı numunelerde boy/çap oranı ve basınç dayanımı arasındaki ilişki
$75 \mathrm{~mm}$ çaplı numunelerde basınç dayanımları $0.5,1.0$, 1.5 ve 2.0 boy/çap oranları için sırasıyla $35.3,29.2,27.5$ ve $26.5 \mathrm{MPa}$ olarak belirlenmiștir. $75 \mathrm{~mm}$ çaplı numunelerde de boy/çap oranının artması ile basınç dayanımlarında azalmalar tespit edilmiştir. Boy/çap oranı $0.5,1.0$ ve 1.5 olan numunelerin basınç dayanımları, boy/çap oranı 2.0 olması durumunda sirasiyla \%24.9, \%9.2 ve \%3.6'ya varan oranlarda azalmıştır. $75 \mathrm{~mm}$ çaplı numunelerde boy/çap oranı ve basınç dayanımları arasında $\mathrm{R}^{2}=0.846$ olacak şekilde $50 \mathrm{~mm}$ çaplı numunelere oranla daha kuvvetli bir doğrusal bir ilişki olduğu belirlenmiştir (Şekil 4).

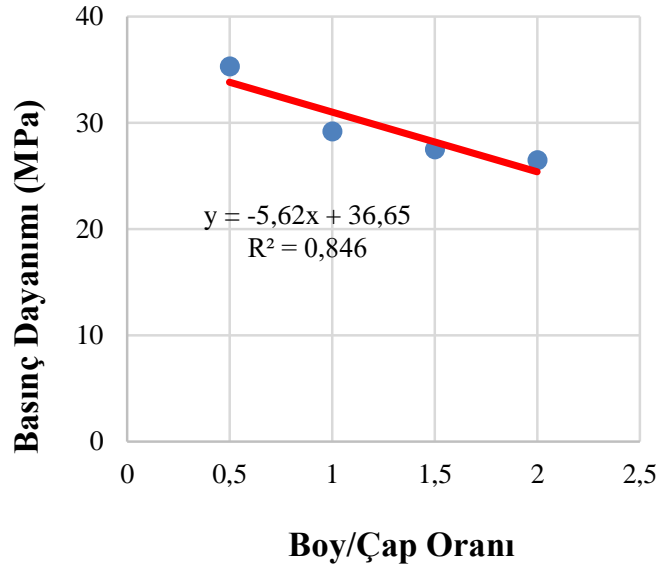

Şekil 4. $75 \mathrm{~mm}$ çaplı numunelerde boy/çap oranı ve basınç dayanımı arasındaki ilişki

$100 \mathrm{~mm}$ çaplı numunelerde basınç dayanımları $0.5,1.0$, 1.5 ve 2.0 boy/çap oranları için sırasıyla 34.5, 29.0, 26.9 ve 25.9 MPa olarak ölçülmüştür. $100 \mathrm{~mm}$ çaplı numunelerde de boy/çap oranının artması ile basınç dayanımları azalmıştır. Boy/çap oranı $0.5,1.0$ ve 1.5 olan numunelerin basınç dayanımları, boy/çap oranı 2.0 olması durumunda sırasıyla $\% 24.9, \% 10.7$ ve $\% 3.7$ oranlarında düşüş göstermiştir. 100 $\mathrm{mm}$ çaplı numunelerin boy/çap oranı ve basınç dayanımları arasında $\mathrm{R}^{2}=0.8796$ olacak şekilde 50 ve $75 \mathrm{~mm}$ çaplı numunelere oranla daha kuvvetli bir doğrusal bir iliş̧ki olduğu tespit edilmiştir. (Şekil 5).

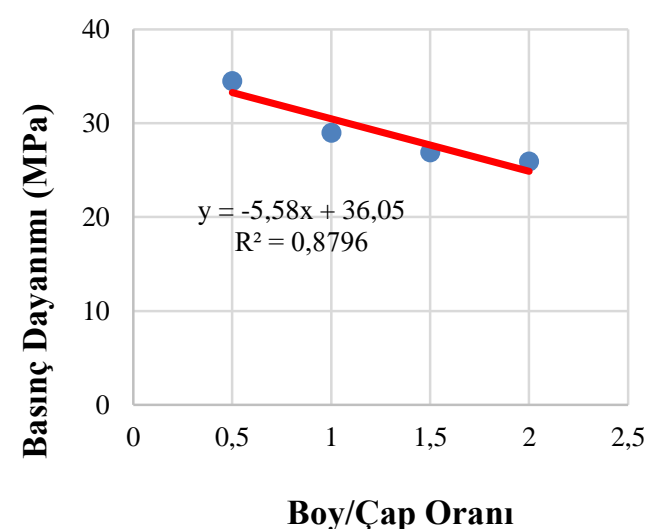

Şekil 5. $100 \mathrm{~mm}$ çaplı numunelerde boy/çap oranı ve basınç dayanımı arasındaki ilişki 
$125 \mathrm{~mm}$ çaplı numunelerde basınç dayanımları $0.5,1.0$, 1.5 ve 2.0 boy/çap oranları için sırasıyla 34.2, 27.7, 26.2 ve 25.7 MPa olarak belirlenmiştir. $125 \mathrm{~mm}$ çaplı numunelerde de diğer numunelere benzer şekilde boy/çap oranının artması ile basınç dayanımlarında azalmalar görülmüştür. Boy/çap oranı $0.25,0.5,1.0$ ve 1.5 olan numunelerin basınç dayanımları, boy/çap oranı 2.0 olduğunda sırasıyla \%24.8, $\% 7.2$ ve \%1.9 oranlarında düşüş göstermiştir. $125 \mathrm{~mm}$ çaplı numuneler için boy/çap oranı ve basınç dayanımları arasında da $\mathrm{R}^{2}=0.7881$ olacak şekilde doğrusal bir ilişki olduğu görülmüştür (Şekil 6).

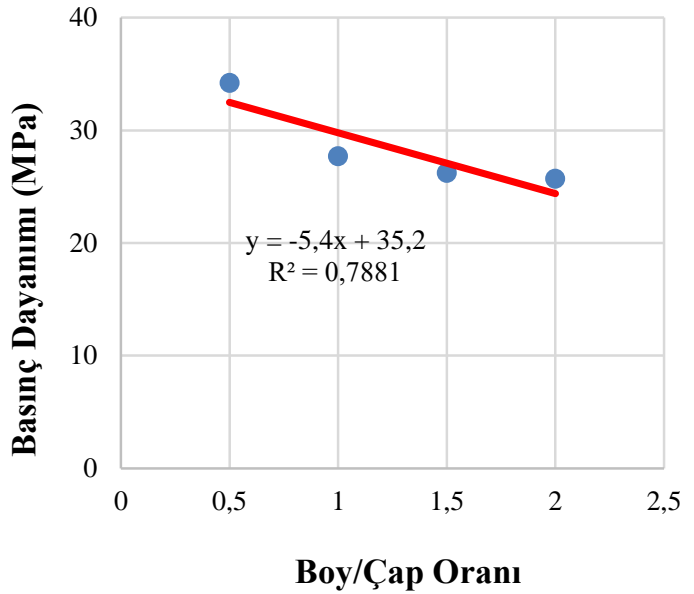

Şekil 6. $125 \mathrm{~mm}$ çaplı numunelerde boy/çap oranı ve basınç dayanımı arasındaki ilişki

$150 \mathrm{~mm}$ çaplı numunelerde basınç dayanımları 0.5, 1.0, 1.5 ve 2.0 boy/çap oranları için sırasıyla 33.7, 26.9, 25.1 ve 24.5 MPa olarak belirlenmiştir. $150 \mathrm{~mm}$ çaplı numunelerde de diğer numunelerde olduğu gibi boy/çap oranının artması ile basınç dayanımları azalmıştır. Boy/çap oranı $0.5,1.0$ ve 1.5 olan numunelerin basınç dayanımları, boy/çap oranı 2.0 olduğunda sırasıyla \%27.3, \%8.9 ve \%2.4 oranlarında düşüş göstermiştir. $150 \mathrm{~mm}$ çaplı numuneler için boy/çap oranı ve basınç dayanımları arasındaki doğrusal ilişki $\mathrm{R}^{2}=0.8071$ olarak tespit edilmiştir (Şekil 7).

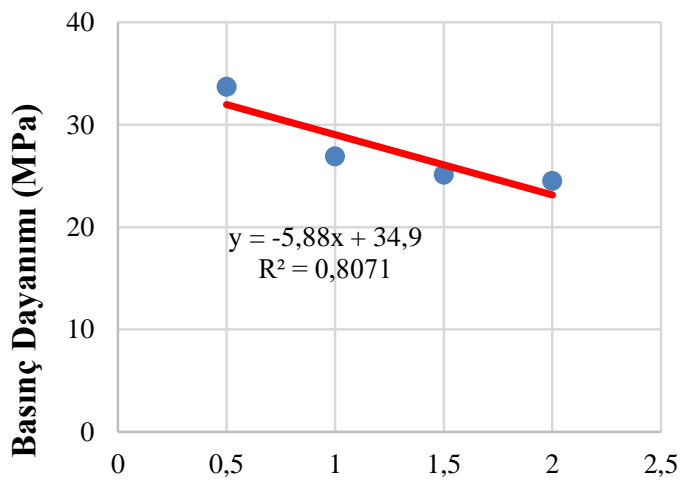

Boy/Çap Oranı

Şekil 7. $150 \mathrm{~mm}$ çaplı numunelerde boy/çap oranı ve basınç dayanımı arasındaki ilişki
Genel olarak tüm numunelerde boy/çap oranı artışı ile basınç dayanımlarında azalmalar meydana gelmiştir [12]. Ortaya çıkan azalmalar incelendiğinde boy/çap oranı 0.5 olan numunelerin basınç dayanımlarının tüm çaplarda boy/çap oranı 2.0 olması durumuna göre yaklaşı $\% 25$ oranında azaldığı görülmüştür. Diğer taraftan numunelerin boy/çap oranı 1.0 ve 1.5 olması durumunda boy/çap oran 12.0 olan numunelere kıyasla basınç dayanımı azalması \%10'dan daha az olmuştur. $\mathrm{Bu}$ durum beton numunelerde deney esnasında deney cihazı tablası ile beton numunesi arasındaki sürtünme kuvvetinin boy/çap oranı düşük olan numunelerde daha büyük olmasına bağlanmaktadır. Çünkü sürtünme kuvveti etkisiyle boy/çap oranı düşük olan numunelerin basınç dayanımı daha yüksek çıkabilmektir [2]. Bu etki boy/çap oranı 0.5 olan numunelerde daha belirgin olurken boy/çap oranı 1.0 ve 1.5 olan numunelerde sonuçları daha az etkilemiştir.

Ayrıca numunelerin çapı da basınç dayanımını etkilemiştir. Aynı boy/çap oranlarında çapı küçük olan numunelerin basınç dayanımları daha yüksek çıkmıştır. Örneğin; $50 \mathrm{~mm}$ çaplı numunede boy/çap oranı 2.0 iken basınç dayanımı $28.2 \mathrm{MPa}$ olarak bulunmuştur. Aynı boy/çap oranında $75,100,125$ ve $150 \mathrm{~mm}$ çaplı numunelerde ise basınç dayanımları sırasıyla $26.5,25.9,25.7$ ve 24.5 olarak bulunmuştur. $\mathrm{Bu}$ durum küçük boyutlu numunelerde kusurlu bölge bulunma ihtimali daha az olurken, büyük boyutlu numunelerde daha fazla olması ile açıklanmaktadır [2]. Literatürde yer alan diğer çalışmalar da boy/çap oranının azalması ile basınç dayanımlarında azalmalar olduğu gözlenmiştir [18, 26]. Bu anlamda çalışma sonuçlarının literatürde yer alan çalışmalar ile uyumluluk gösterdiği söylenebilir.

Diğer taraftan çalışmada elde edilen sonuçlar ile ASTM C42 [27] standardına göre boy/çap oranı 1-2 arasında olan numuneler için verilen dayanım düzeltme katsayıları Tablo 4'de karşılaştırılmıştır. Tablo 4 incelendiğinde ASTM standardına göre boy/çap oranı 1.0 ve 1.5 olan silindirik numuneler için narinlik etkisine bağlı olarak dayanım düzeltme katsayıları sırasıyla 0.87 ve 0.96 olarak verilmiştir. Çalışmada elde edilen sonuçlara göre $0.5,1.0$ ve 1.5 boy/çap oranına bağlı olarak elde edilen dayanım düzeltme katsayıları sırasıyla $\quad 0.73-0.77, \quad 0.89-0.95, \quad 0.96-0.98$ aralığında değişmektedir. Boy/çap oranı 1.0 olan numunelerde ASTM C42 standardına göre daha yüksek değerler elde edilirken, boy/çap oranı 1.5 olan numuneler için standartta verilen değerlere yakın sonuçların elde edildiği görülmüştür.

Tablo 4. Farklı boy/çap oranları için dayanım düzeltme katsayıları

\begin{tabular}{ccccccc}
\hline \multicolumn{7}{c}{ Dayanım düzeltme katsayıs1 } \\
\hline $\mathrm{h} / \mathrm{d}$ & ASTM C42 & $50 \mathrm{~mm}$ & $75 \mathrm{~mm}$ & $100 \mathrm{~mm}$ & $125 \mathrm{~mm}$ & $150 \mathrm{~mm}$ \\
\hline 2.0 & 1.00 & 1.00 & 1.00 & 1.00 & 1.00 & 1.00 \\
1.5 & 0.96 & 0.98 & 0.96 & 0.96 & 0.98 & 0.98 \\
1.0 & 0.87 & 0.95 & 0.91 & 0.89 & 0.93 & 0.91 \\
0.5 & - & 0.77 & 0.75 & 0.75 & 0.75 & 0.73 \\
\hline
\end{tabular}




\section{Sonuçlar}

$\mathrm{Bu}$ çalışmada, boy/çap oranı değişiminin basınç dayanımına etkisi; farklı çaplarda üretilen ve basınç dayanımına tabi tutulan silindirik numuneler üzerinde deneysel olarak incelenmiştir. Elde edilen bulgular aşağıda sunulmuştur.

- Tüm numunelerde, numunelerin çaplarından bağımsız olarak boy/çap oranı arttıkça basınç dayanımlarında azalmalar gözlenmiştir. Bu azalma boy/çap oranı 0.5 'den 2.0'ye doğru arttıkça \%25 seviyelerine kadar ulaşmıştır.

- Boy/çap oranı 0.50 olan numunelerde basınç dayanımları tüm çaplarda diğer numunelere oranla daha yüksek çıkmıştır. Boy/çap oranı 1.0, 1.5 ve 2.0 olan numunelerin basınç dayanımları ise birbirlerine oldukça yakın çıkmıştır.

- Aynı boy/çap oranlarında çapı küçük olan numunelerin basınç dayanımları daha yüksek çıkmıştır.

- Boy/çap oranı ve basınç dayanımları arasındaki ilişki incelendiğinde tüm çaplarda boy/çap oranı ve basınç dayanımları arasında \%75-\%88 arasında değişen oranlarda doğrusal bir ilişki olduğu tespit edilmiştir. Boy/çap oranı ve basınç dayanımları arasındaki en kuvvetli doğrusal ilişki ise \%88 ile 100 mm çaplı numunelerde görülmüştür

\section{Çıkar çatışması}

Yazar çıkar çatışması olmadığını beyan etmektedir.

\section{Benzerlik oranı (iThenticate): \%6}

\section{Kaynaklar}

[1] T. Erdoğan, Beton, 5th ed. Ankara, Turkey: Odtü Yayıncılık, 2015.

[2] B. Baradan, H. Yazıcı ve S.Aydın, Beton, 2nd ed. İzmir, Türkiye: Dokuz Eylül Üniversitesi Mühendislik Fakültesi Yayınları, 2015.

[3] O. Şimşek, Beton ve Beton Teknolojisi, 5th ed. Ankara, Türkiye: Seçkin Yayıncılık, 2016.

[4] TS 13515, Complementary Turkish Standard for the implementation of TS EN 206. Ankara, Turkey: TSE, 2019.

[5] Z. Algın, K. Mermerdaş ve M. S. Zeynepli, Silindirle sıkıştırılmış betonda makro sentetik elyaf kullanımının optimum su içeriğine ve betonun dayanım özelliklerine etkisi, Ömer Halisdemir Üniversitesi Mühendislik Bilim. Derg., 8(2),.992-1004,2019. https://doi.org/ $\% 2010.28948 /$ ngumuh.534055.

[6] C. Demirel ve A. Gökdemir, Çeper etkisi oluşmayan farklı biçim ve boyuttaki beton numunelerin basınç dayanımlarının deneysel karşılaştırılması, SDU Int. Technol. Sci., 6(3), 29-48, 2014.

[7] F. Özcan, Niğde bölgesinde üretilen hazır betonların elastisite modüllerinin belirlenmesi, Ömer Halisdemir Üniversitesi Mühendislik Bilim. Derg., 7(1), 260-265, 2018. https://doi.org/ 10.28948/ngumuh.386696

[8] K. Güçlüer, O. Günaydın, Ö. F. Tekin ve M. F. Şahan, Farklı tipte agrega kullanımının betonun mekanik özeliklerine etkisinin araştırılması, Ömer Halisdemir Üniversitesi Mühendislik Bilim. Derg., 6(1), 107-114, 2017.
[9] İ. İ. Atabey, S. Çelikten ve Ü. Yurt, Farklı mineral katkılı yüksek dayanımlı betonlarda metagabro agregalarının kullanılabilirliğinin araştırılması, Acad. Platf. J. Eng. Sci., 8(3), 514-522, 2020. https://doi.org/10.21541/apjes.708245.

[10] Z. P. Bažant, Size effect in blunt fracture: concrete, rock, metal, J. Eng. Mech., 1984. https://doi.org/10.1061/(asce)07339399(1984)110:4(5 $18)$.

[11] M. S. Chin, M. A. Mansur, and T. H. Wee, Effects of shape, size, and casting direction of specimens on stress-strain curves of high-strength concrete, ACI Mater. J., 1997. https://doi.org/10.14359/301.

[12] J. R. del Viso, J. R. Carmona, and G. Ruiz, Shape and size effects on the compressive strength of highstrength concrete, Cem. Concr. Res., 2008. https://doi.org/10.1016/j.cemconres.2007.09.020.

[13] A. Malaikah, Effect of Specimen Size and Shape on the Compressive Strength of High Strength Concrete, Pertanika J. Sci. Technol., 2005. https:// doi.org/10.1051/matecconf/20141002003.

[14] Y. Che, S. Ban, J. Cui, G. Chen, and Y. Song, Effect of specimen shape and size on compressive strength of concrete, Adv. Mater. Res., 2011. https://doi.org/ 10.1028/www.scientific.net/AMR.163-167.1375.

[15] M. Saridemir, Effect of specimen size and shape on compressive strength of concrete containing fly ash: Application of genetic programming for design, Mater. Des., 2014. https://doi.org/10.1016/j.matdes.2013. 10.073 .

[16] I. M. Nikbin, M. Dehestani, M. H. A. Beygi, and M. Rezvani, Effects of cube size and placement direction on compressive strength of self-consolidating concrete, Constr. Build. Mater., 2014. https://doi.org/ 10.1016/j.conbuildmat.2014.02.008.

[17] M. R. Wisnom, Size effects in composites, in Comprehensive Composite Materials II, 2017.

[18] S. T. Yi, E. I. Yang, and J. C. Choi, Effect of specimen sizes, specimen shapes, and placement directions on compressive strength of concrete, Nucl. Eng. Des., 2006. https://doi.org/10.1016/j.nucengdes.2005. 08.004 .

[19] H. Sert, Beton Karot Dayanımları ile Standart Silindir Dayanımları Arasındaki İlişkinin Karot Çapına Bağlı Olarak Belirlenmesi, Erciyes Üniversitesi, Fen Bilimleri Enstitüsü, Yüksek Lisans Tezi, 2011.

[20] M. Tokyay and M. Özdemir, Specimen shape and size effect on the compressive strength of higher strength concrete, Cem. Concr. Res., 1997. https://doi.org/ 10.1016/S00088846(97)00104-X.

[21] TS EN 933-1, Tests for geometrical properties of aggregates - Part 1: Determination of particle size distribution - Sieving method. Ankara, Turkey: TSE, 2012.

[22] TS 802, Design of concrete mixes. Ankara, Turkey, 2016.

[23] TS 1247, Concrete mixing, casting and maintenance rules (under normal weather conditions). Ankara, Turkey, 2018. 
[24] TS EN 12504-1, Testing concrete in structures - Part 1: Cored specimens - Taking, examining and testing in compression. Ankara, Turkey, 2019.

[25] TS EN 12390-3, Testing hardened concrete - Part 3: Compressive strength of test specimens. Ankara, Turkey, 2019.
[26] A. J. Hamad, Size and shape effect of specimen on the compressive strength of HPLWFC reinforced with glass fibres, J. King Saud Univ. - Eng. Sci., 2017. https://doi.org/doi:10.1016/j.jksues.2015.09.003.

[27] ASTM, C42/C42M -03 Standard Method of Test for Obtaining and Testing Drilled Cores and Sawed Beams of Concrete. 2004. 